\title{
Evaluating the impact of targeting livestock for the prevention of human and animal trypanosomiasis, at village level, in districts newly affected with $T$. $b$. rhodesiense in Uganda
}

Louise Hamill', Kim Picozzi ${ }^{1}$, Jenna Fyfe ${ }^{1}$, Beatrix von Wissmann ${ }^{1}$, Sally Wastling ${ }^{1}$, Nicola Wardrop ${ }^{1}$, Richard Selby ${ }^{1}$ Christine Amongi Acup ${ }^{1}$, Kevin L. Bardosh', Dennis Muhanguzi ${ }^{2}$, John D. Kabasa², Charles Waiswa ${ }^{2,3}$ and Susan C. Welburn ${ }^{1 *}$

\begin{abstract}
Background: Uganda has suffered from a series of epidemics of Human African Trypanosomiasis (HAT), a tsetse transmitted disease, also known as sleeping sickness. The area affected by acute Trypanosoma brucei rhodesiense HAT ( $r H A T)$ has been expanding, driven by importation of infected cattle into regions previously free of the disease. These regions are also affected by African Animal Trypanosomiasis (AAT) demanding a strategy for integrated disease control.

Methods: In 2008, the Public Private Partnership, Stamp Out Sleeping Sickness (SOS) administered a single dose of trypanocide to 31486 head of cattle in 29 parishes in Dokolo and Kaberamaido districts. This study examines the impact of this intervention on the prevalence of rHAT and AAT trypanosomes in cattle from villages that had (HAT ${ }^{+v e}$ ) or had not (HAT ${ }^{\mathrm{ve}}$ ) experienced a recent case of rHAT. Cattle herds from 20 villages were sampled and screened by PCR, pre-intervention and 6-months post-intervention, for the presence or absence of: Trypanosoma brucei s.l.; human infective T. b. rhodesiense; Trypanosoma vivax; and Trypanosoma congolense savannah.
\end{abstract}

Results: Post-intervention, there was a significant decrease in the prevalence of $T$. brucei s.l. and the human infective sub-species T. b. rhodesiense in village cattle across all 20 villages. The prevalence of $T$. b. rhodesiense was reduced from $2.4 \%$ to $0.74 \%(P<0.0001)$, with the intervention showing greater impact in HAT ${ }^{\text {ve }}$ villages. The number of villages containing cattle harbouring human infective parasites decreased from 15/20 to 8/20, with T. b. rhodesiense infection mainly persisting within cattle in $\mathrm{HAT}^{+\mathrm{ve}}$ villages (six/eight). The proportion of T. brucei s.l. infections identified as human infective T. b. rhodesiense decreased after the intervention from $8.3 \%(95 \% \mathrm{Cl}=11.1-5.9 \%)$ to $4.1 \%(95 \% \mathrm{Cl}=6$. 8-2.3\%). Villages that had experienced a recent human case (HAT ${ }^{\text {tve }}$ villages) showed a significantly higher prevalence for AAT both pre- and post-intervention. For AAT the prevalence of T. vivax was significantly reduced from $5.9 \%$ to 0 . 05\% post-intervention while the prevalence of T. congolense increased from $8.0 \%$ to $12.2 \%$.

(Continued on next page)

\footnotetext{
* Correspondence: sue.welburn@ed.ac.uk

${ }^{1}$ Edinburgh Infectious Diseases, Division of Infection and Pathway Medicine, Edinburgh Medical School: Biomedical Sciences, The University of Edinburgh, Chancellor's Building, 49 Little France Crescent, Edinburgh EH16 4SB, UK Full list of author information is available at the end of the article
} 
(Continued from previous page)

Conclusions: The intervention resulted in a significant decrease in the prevalence of T. brucei s.l., human infective T. b. rhodesiense and T. vivax infection in village cattle herds. The proportion of T. brucei s.l. that were human infective, decreased from 1:12 T. brucei s.l. infections before the intervention to 1:33 post-intervention. It is clearly more difficult to eliminate T. b. rhodesiense from cattle in villages that have experienced a human case. Evidence of elevated levels of AAT in livestock within village herds is a useful indicator of risk for rHAT in Uganda. Integrated veterinary and medical surveillance is key to successful control of zoonotic rHAT.

Keywords: African animal trypanosomiasis (AAT), Human African trypanosomiasis (HAT), Sleeping sickness, Trypanosma brucei rhodesiense HAT (rHAT), Uganda, T. b. brucei, T. b. rhodesiense

\section{Multilingual abstracts}

Please see Additional file 1 for translations of the abstract into the five official working languages of the United Nations.

\section{Background}

Human African Trypanosomiasis (HAT) or sleeping sickness, comprises two distinct tsetse transmitted parasitic diseases, both of which are fatal if they are not treated: chronic, Trypanosoma brucei gambiense HAT (gHAT) and acute Trypanosoma brucei rhodesiense HAT (rHAT) [1]. Uganda has active foci for both rHAT and gHAT which have been geographically separated for more than a century $[1,2]$. gHAT lies in the northwest in districts adjacent to South Sudan and is relatively stable [3] while the area affected by rHAT, originally restricted to the shores of Lake Victoria [4] began expanding from the mid-1980s. An rHAT epidemic began in Tororo district in the mid1980s spreading to Butaleja and Busia districts [5-7] spreading to Soroti and Serere districts in $2000[7,8]$ and subsequently to Kaberamaido and Dokolo districts by 2004 $[9,10]$. By 2005 , the areas affected by gHAT and rHAT were only $150 \mathrm{~km}$ apart [11].

The causal agent of rHAT, $T . b$. rhodesiense, co-exists in a range of non-human hosts [12] with a suite of other trypanosomes that cause African Animal Trypanosomiasis (AAT). A series of studies showed that cattle in Uganda carried human infective $T . b$. rhodesiense $[6,7,9]$ and that movements of infected cattle from districts within the rHAT focus to rHAT free districts $[8,13]$ were responsible for the spread of rHAT in Uganda. The epidemic in Soroti was directly linked to importation of cattle through Brooks Corner cattle market [8].

Both HAT and AAT are major priorities for Uganda [14, 15] with approximately one-third of the national herd at risk from AAT [15], with serious economic losses [16]. Infection with $T . b$. rhodesiense in indigenous cattle is largely asymptomatic; livestock in rural areas of Uganda are not routinely treated unless they show co-infection with $T$. congolense or T. vivax. Cattle are long-term investments and untreated infected animals comprise a persistent zoonotic reservoir of rHAT parasites posing a threat to human health.
The expansion of the rHAT focus poses a significant health risk (Fig. 1) and convergence of the gHAT and rHAT foci would compromise existing approaches for diagnosis and treatment [17]. T. $b$. rhodesiense HAT is significantly under-reported [18] and identification of human cases remains a challenge to the health system [19]. Controlling rHAT requires veterinary intervention [20]. A single trypanocidal intervention, targeted to cattle in Kamuli and Soroti districts, at high risk for rHAT in 2002 reduced the prevalence of T. b. brucei s.l. and T. b. rhodesiense and resulted in a significant decrease in human rHAT cases [21] suggesting that if sufficient head of cattle were treated, rHAT transmission could be stopped [22]. In 2006, a Public Private Partnership, Stamp Out Sleeping Sickness (SOS) [23], aimed to remove the reservoir of $T$. b. rhodesiense in Soroti, Dokolo, Lira, Apac and Kaberamaido districts by mass treating cattle [24].

Here we examine the impact of mass cattle trypanocidal intervention on the parasite burden (T. brucei s.l., T. vivax and $T$. congolense and human infective $T . b$.rhodesiense parasites) in cattle within the SOS intervention zone, at village level, examining villages that had and had not previously experienced a human case of rHAT.

\section{Methods \\ Description of the study area}

The study area comprised Kaberamaido and Dokolo districts (in the Eastern and Northern regions respectively) in Uganda, which have been affected by rHAT since 2004. The districts border the northern shore of Lake Kyoga with a combined area of approximately $2467 \mathrm{~km}^{2}$ and a human population of approximately 261000 [25]. The main economic activities within the study area are agriculture and fishing, with the majority of the population engaged in subsistence farming [26]. The first cases of rHAT were reported in Kaberamaido and Dokolo districts in 2004 and the continued presentation of new cases indicates active transmission in both districts. A mass chemotherapuetic intervention was undertaken in cattle, in these districts in 2006, in an attempt to prevent the northwards spread of rHAT [24]. According to the livestock census undertaken in 2008, Dokolo had 58902 cattle and Kaberamaido 76109 cattle (Table 1). 


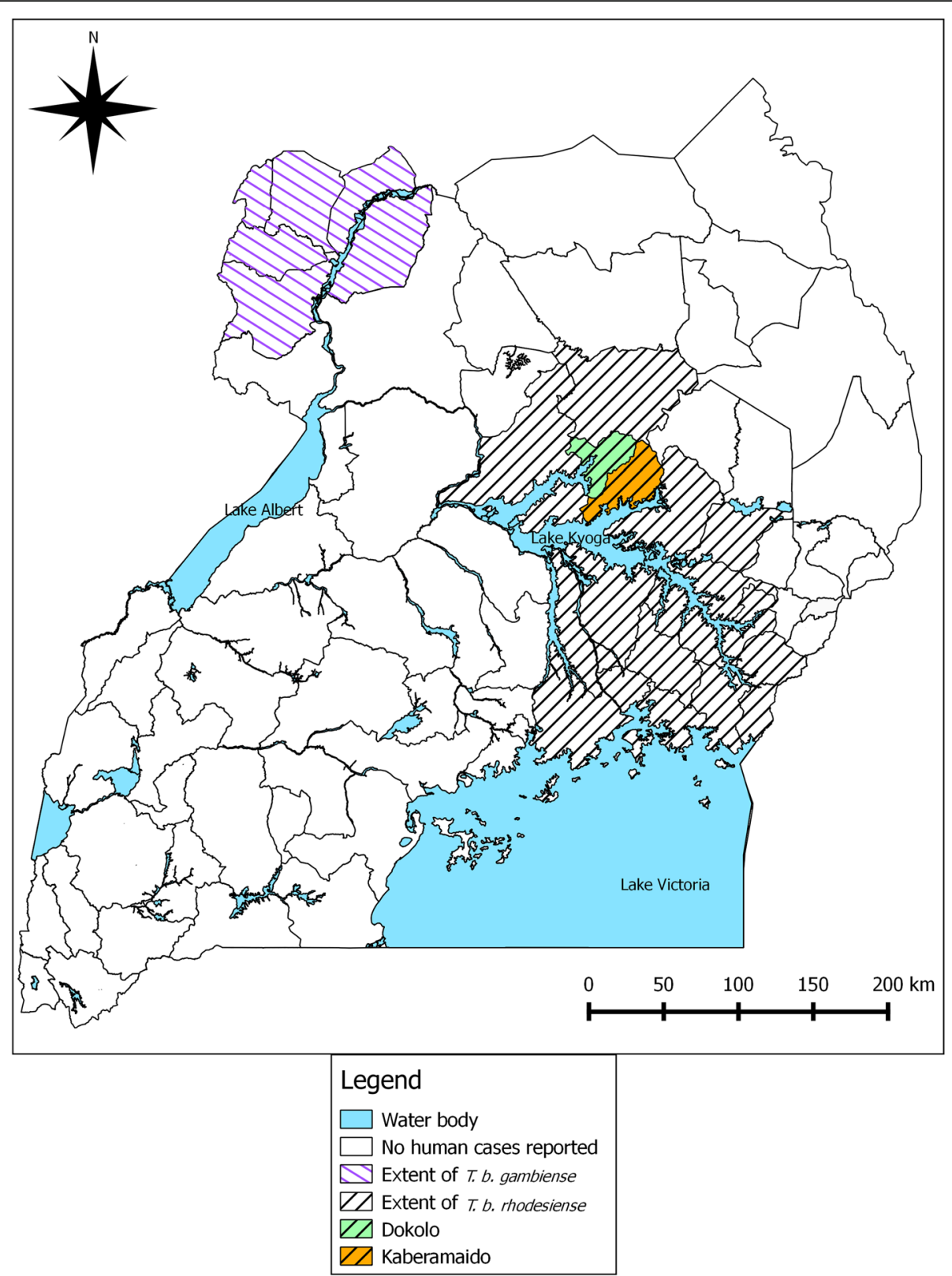

Fig. 1 Districts of Uganda affected by T. b. rhodesiense HAT (rHAT) and T. b. gambiense HAT (gHAT). Study districts, Dokolo and Kaberamaido, are indicated

Table 1 Demographic data for Dokolo and Kaberamaido districts

\begin{tabular}{lllll}
\hline District & $\begin{array}{l}\text { Human population } \\
\text { (2002 census) }\end{array}$ & $\begin{array}{l}\text { Cattle population } \\
\text { (2008 census) }\end{array}$ & $\begin{array}{l}\text { Land area }\left(\mathrm{km}^{2}\right) \\
(1995 \text { census) }\end{array}$ & $\begin{array}{l}\text { Estimated cattle } \\
\text { density }\left(\mathrm{km}^{2}\right)\end{array}$ \\
\hline Dokolo & 129385 & 58902 & 1113 & 53 \\
Kaberamaido & 131650 & 76109 & 1354 & 56 \\
\hline
\end{tabular}

N.B. Figures derived from the Ugandan Bureau of Statistics. Land mass for Kaberamaido excludes open water areas ( $269 \mathrm{~km}^{2}$ for) but includes seasonal and permanent wetlands $\left(144 \mathrm{~km}^{2}\right)$. Land/water area data for Dokolo district was not available, but this district has relatively small open water and wetland areas 


\section{Description of the intervention}

Between April and May 2008, due to the persistence of rHAT cases in parishes lying on the border between Dokolo and Kabaramiado [10, 27], a further intervention, comprising a single dose of trypanocide, was given to 31486 cattle across 29 rHAT affected parishes (Table 2). All villages in the districts were georeferenced using hand held global positioning systems prior to the intervention (GPS: Garmin, E-trex venture) [26]. Intervention sites were selected at parish level (between 3-10 villages); an average village had less than 100 households with between 30 and $50 \%$ of households owning cattle, typically small herds of 3-10 cattle although some larger herds of 50-100 cattle were present [28]. All available village cattle were injected with a single dose of Veriben (diminazene aceturate - Ceva Santé Animale) at $7.5 \mathrm{mg} / \mathrm{kg}$; at the same time a single application of the insecticide Vectocid (Ceva Santé Animale) was applied to the legs and belly [29-31]. Treatment coverage data was obtained from estimates based on the total number of cattle treated in the parishes under the SOS intervention and from farmer reporting of intervention status of cattle sampled 6 months after intervention.

\section{Study design}

To examine the parasite dynamics before and after intervention, two groups of villages were selected: villages that had experienced a case of human rHAT in the previous 6 months $\left(\mathrm{rHAT}^{+\mathrm{ve}}\right.$ villages) and those that had never reported a case ( rHAT $^{-v e}$ villages). Records detailing all rHAT patients between January and June 2007 were obtained from the two health centres established for treatment of rHAT in Dokolo and Kaberamaido: Lwala health centre in Kaberamaido district and Serere health centres in Soroti district [18]. Cases were cross-referenced to the georeferenced village data to classify all villages into two groups: case villages and no-case villages. A case village $\left(\mathrm{rHAT}^{+\mathrm{ve}}\right.$ village) was defined as having one or more rHAT cases diagnosed in the 6 month period January - June 2007. Twenty villages were randomly selected to monitor the impact of the intervention: 10 rHAT $^{+v e}$ villages that had reported a rHAT case between January - June 2007 and 10 that had never reported a case (HAT $^{\text {-ve }}$ villages). Figure 2 shows the location of all study villages and the intervention sites. The village HAT case status is shown in Fig. 3 which also indicates the location of the HAT treatment centre.

\section{Sample size calculation}

The required sample size was based on the requirement for comparing two proportions (rHAT case vs. non rHAT case villages) [32], with adjustment for cluster sampling [33] at the village level. An estimated T. brucei s.l. prevalence of $20 \%$ was used, alongside an intercluster variance $\left(\mathrm{V}_{\mathrm{c}}\right)$ of 0.013 [34] to allow for a differences in trypanosome prevalence to be detected at $95 \%$ confidence and $80 \%$ power [32]. This called for a

Table 2 Cattle treated March to April 2008 in Dokolo and Kaberamaido districts (percentage of the estimated total cattle population by parish)

\begin{tabular}{|c|c|c|c|c|c|c|c|}
\hline \multicolumn{4}{|l|}{ Dokolo district } & \multicolumn{4}{|c|}{ Kaberamaido district } \\
\hline Parish & Estimated population & Number treated & $\%$ & Parish & Estimated population & Number treated & $\%$ \\
\hline Anwangi/Amwoma & 2503 & 1962 & 78 & Oguolo & 1206 & 1998 & 166 \\
\hline Aneralibi & 1252 & 1044 & 83 & Amoru & 840 & 3036 & 361 \\
\hline Iguli & 1050 & 867 & 83 & Kalaki & 1554 & 903 & 58 \\
\hline Adwila & 1638 & 660 & 40 & Kadie & 752 & 1554 & 207 \\
\hline Angwenya & 400 & 1253 & 313 & Opiltok & 162 & 1701 & 1050 \\
\hline Akurolango & 1242 & 2117 & 171 & Lwala & 561 & 909 & 162 \\
\hline Angwecibange/Atur & 882 & 656 & 75 & Olelai & 1311 & 1538 & 117 \\
\hline Alwithmac & 800 & 760 & 95 & Oryamo & 584 & 1261 & 216 \\
\hline Adagmon & 1000 & 488 & 49 & Abalang & 1500 & 701 & 47 \\
\hline Awiri & 513 & 578 & 127 & Acanpi & 790 & 420 & 53 \\
\hline \multirow[t]{6}{*}{ Aderolongo } & 529 & 435 & 82 & Kamuk & 1503 & 783 & 52 \\
\hline & & & & Okile & 972 & 2466 & 254 \\
\hline & & & & Abal-kweru & 1037 & 993 & 96 \\
\hline & & & & Kaberamaido & 873 & 188 & 22 \\
\hline & & & & Plantau & 1804 & 1051 & 58 \\
\hline & & & & Katinge & 1470 & 1164 & 79 \\
\hline TOTAL & 11809 & 10820 & $91.6 \%$ & TOTAL & 16919 & 20666 & $122 \%$ \\
\hline
\end{tabular}




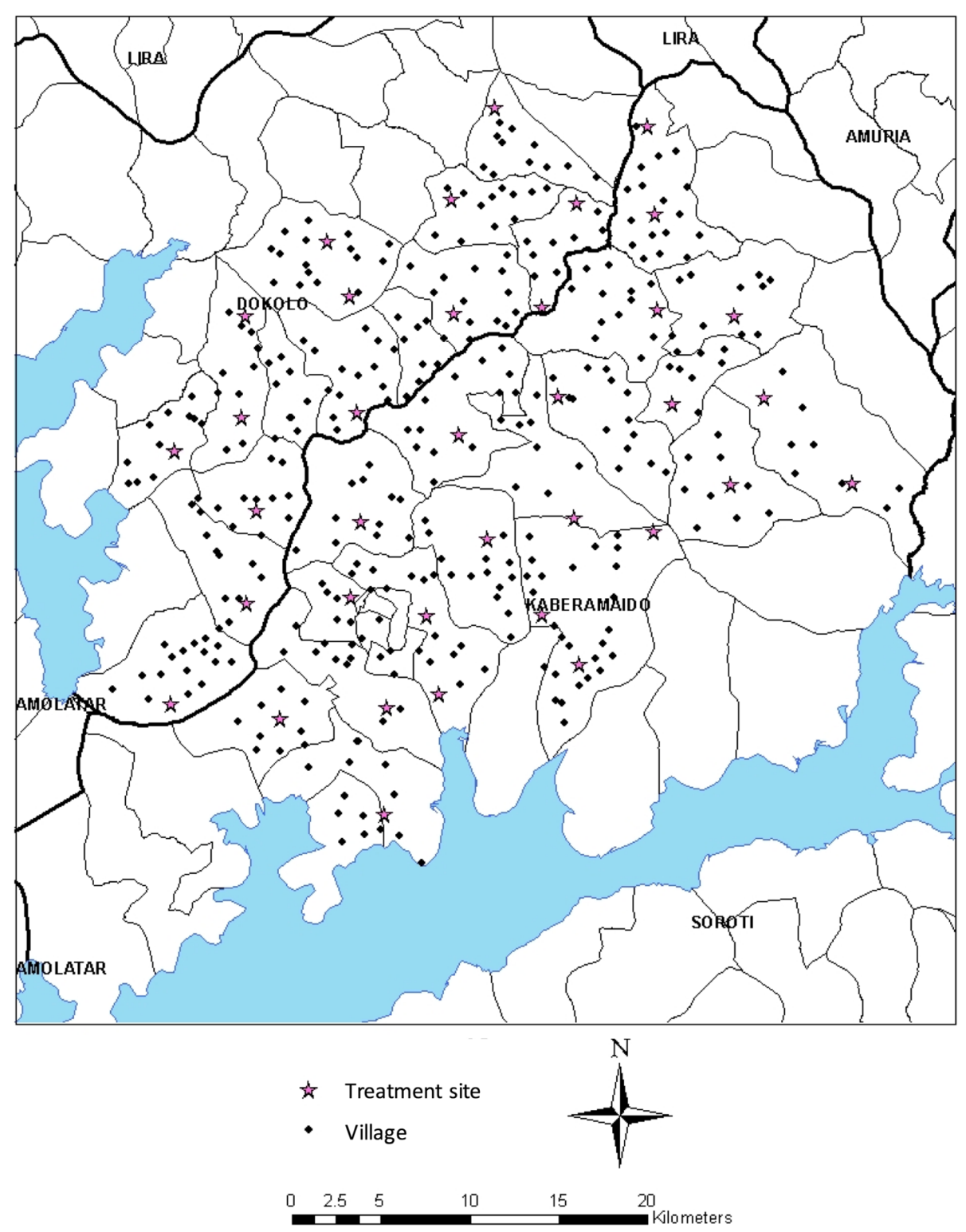

Fig. 2 Location of study village and intervention (treatment sites) in Dokolo and Kaberamaido districts

minimum sample number of 67 individual cattle per cluster, across 20 village clusters $(1340)$. Cattle were systematically sampled by order of presentation at each village sampling site, up to a maximum of 100 animals per village, to maintain sufficient sample size of cattle from rHAT case and non-rHAT case villages overall, and to compensate for villages with fewer than 67 cattle.

\section{Sample collection}

Samples of blood $(100 \mu \mathrm{l})$ were taken from the ear vein of cattle in the rHAT+ve (case) villages and rHAT+ve (no case) villages, before (April - May 2008) and 6 months after intervention (October 2008). In total 3549 cattle were sampled: 1658 before intervention and 1891 after
6 months intervention. Before taking blood samples, the livestock owner was asked whether the animal had been treated during the mass intervention.

One hundred microliters of blood was drawn from the ear capillary using a lancet, collected into two $50 \mu \mathrm{l}$ capillary tubes and spotted on a $\mathrm{FTA}^{\mathrm{mm}}$ card (Whatman, Maidstone, Kent, UK). Cards were air dried at room temperature for $24 \mathrm{~h}$ and stored in multi-barrier pouches with desiccant (Whatman, UK).

\section{Laboratory analysis}

Samples were analysed by PCR to identify all trypanosome species and subspecies present. Five $3 \mathrm{~mm}$ discs were punched from each blood sample and processed as 


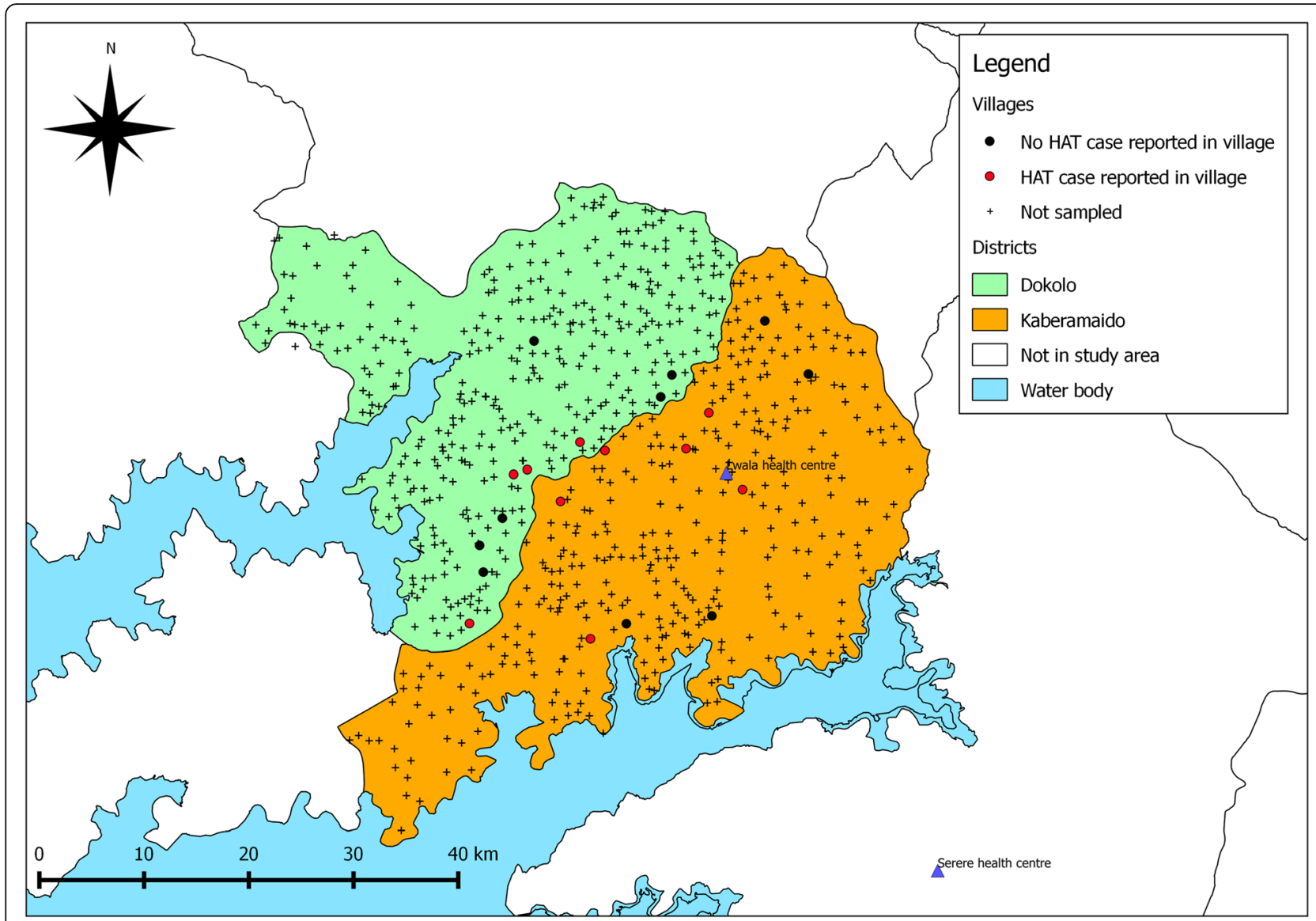

Fig. 3 Location of HAT ${ }^{+v e}$ and HAT ${ }^{-v e}$ study villages in Dokolo and Kaberamaido districts

previously described [35-37]. Discs were washed four times, twice with FTA purification reagent and twice with TE buffer, before being air dried and then heated at $90{ }^{\circ} \mathrm{C}$ for $30 \mathrm{~min}$ suspended in $5 \%(\mathrm{w} / \mathrm{v})$ Chelex solution. Five microliters of eluted sample solution, was used to seed all PCR reactions. Previously published species specific primers were used to detect T. brucei s.l., T. vivax, and $T$. congolense savannah, in three separate PCR reactions [35-37]. Samples positive for T. brucei s.l. were further tested for $T$. $b$. rhodesiense using a multiplex PCR to discriminate $T$. $b$. brucei and T. b. rhodesiense [38]. Standard PCR amplifications for all reactions were carried out in $25 \mu \mathrm{l}$ mixtures; reaction conditions, primer sequences and cycling conditions were as previously published [35-37]. One positive control [genomic deoxyribonucleic acid (DNA)] and one negative control (extract from blank FTA $^{\mathrm{mm}}$ disc) were run with each reaction. PCR products were resolved via electrophoresis on $1.5 \%$ agarose gels using GelRed DNA stain and run at 100v for a minimum of $45 \mathrm{~min}$ in the presence of a molecular marker, until band size could be easily determined. PCR products were visualised and documented with a BioRad GelDock ${ }^{\text {tin }}$ imaging system.

\section{Statistical analysis}

The prevalence of $T$. brucei s.l., $T$. $b$. rhodesiense, T. vivax and $T$. congolense savannah trypanosome infection detected by PCR were expressed as a percentage, and exact binomial 95\% confidence intervals were computed ( $\mathrm{R}$, version 2.0.1). Fisher's Exact test was used to compare trypanosome prevalence in $\mathrm{rHAT}^{+\mathrm{ve}}$ and $\mathrm{rHAT}^{-\mathrm{ve}}$ villages and between the pre- and 6 months post-intervention sampling.

\section{Results}

One thousand six hundred and fifty-eight cattle blood samples were obtained before intervention from the 20 village sites; 854 from animals in $\mathrm{HAT}^{+\mathrm{ve}}$ villages and 804 from cattle in $\mathrm{HAT}^{-\mathrm{ve}}$ villages. Of these, $642 \mathrm{sam}$ ples were positive for one or more species of trypanosome; 362 from $\mathrm{HAT}^{+\mathrm{ve}}$ villages (prevalence 42.4\%, 95\% $C I=45.8-39.1 \%$ ) and 280 were from $\mathrm{HAT}^{-\mathrm{ve}}$ villages (prevalence $34.8 \%, 95 \% C I=38.2-31.5 \%$ ). The prevalence of cattle trypanosomiasis (AAT) was significantly higher in $\mathrm{HAT}^{\text {+ve }}$ villages $(P<0.001)$.

Six months post-intervention, 1891 cattle blood samples were taken from the same 20 villages; 956 from $\mathrm{HAT}^{+\mathrm{ve}}$ villages and 935 from $\mathrm{HAT}^{-\mathrm{ve}}$ villages. Of these 
509 cattle were positive for one or more species of trypanosome; 266 (prevalence 27.8\%, 95\% CI $=30.8-25.0 \%$ ) were from $\mathrm{HAT}^{\text {tve }}$ villages and 243 (prevalence $26.0 \%$, 95\% CI $=28.9-23.2 \%$ ) from $\mathrm{HAT}^{-\mathrm{ve}}$ villages (see Fig. 4).

\section{T. brucei s. I}

T. brucei s.l. was the most common species detected both before and after intervention (Fig. 4). T. brucei s.l. prevalence varied from 15.6 to $53.0 \%$ between villages. The prevalence of $T$. brucei s.l. was significantly higher in $\mathrm{HAT}^{+\mathrm{ve}}$ villages than in $\mathrm{HAT}^{-\mathrm{ve}}$ villages pre-intervention $(P=0.002)$ and post-intervention $(P=0.008)$.

Across all 20 villages, the prevalence of T. brucei s.l. was significantly lower 6 months after the intervention, irrespective of village HAT status. For $\mathrm{HAT}^{+\mathrm{ve}}$ villages, the prevalence of $T$. brucei s.l. in cattle was $31.7 \%$ (271/ 854 95\% $C I=35.0-28.6 \%)$ pre-intervention and significantly lower, $20.4 \%$ (195/956 95\% CI=23.1-17.9\%), post-intervention $(P<0.0001)$. In cattle from villages defined as $\mathrm{HAT}^{-\mathrm{ve}}$, T. brucei s.l. prevalence was $25.0 \%$ (201/804 95\% CI $=28.1-22.0 \%)$ pre-intervention and significantly lower, $15.7 \%(147 / 93595 \% C I=18.2-13.4 \%), 6$ months post-intervention $(P<0.0001)$.

\section{T. b. rhodesiense}

There was a reduction in the prevalence of human infective $T . b$. rhodesiense in cattle 6 months post intervention in both HAT $^{+\mathrm{ve}}$ and $\mathrm{HAT}^{-\mathrm{ve}}$ villages. Across the 20 study villages the prevalence of human infective $T . b$. rhodesiense in cattle was reduced 3-fold, from 2.4\% (39/1658) pre-intervention to $0.74 \% 6$ months post-intervention (14/ 1891). Within the $\mathrm{HAT}^{+\mathrm{ve}}$ villages, pre-intervention, the prevalence of $T . b$. rhodesiense, in cattle was $2.5 \%$ (21/854, 95\% $C I=3.7-1.5 \%)$. This was halved to $1.26 \%(12 / 956$, 95\% $C I=2.2-0.7 \%, P=0.077)$ post-intervention. In cattle from the $\mathrm{HAT}^{-\mathrm{ve}}$ villages the prevalence of $T$. $b$. rhodesiense was $2.2 \%(18 / 804,95 \% C I=3.5-1.3 \%)$ pre-intervention, and this was significantly decreased, by more than 10 fold, post-intervention to $0.2 \%(2 / 935,95 \% C I=0.8-$ $0.0 \%, P<0.0001$ ).

The intervention also impacted in the proportion of human infective $T . b$. rhodesiense within the population of circulating T. brucei s.l. in cattle (Fig. 5). Critically, the proportion of $T . b$. brucei that was $T . b$. rhodesiense (human infective) decreased after intervention. Prior to the intervention in $\mathrm{rHAT}^{+\mathrm{ve}}$ and $\mathrm{rHAT}^{-\mathrm{ve}}$ villages combined $8.3 \%(39 / 472,95 \% C I=11.1-5.9 \%)$ of circulating T. brucei s.l. were human infective; post-intervention this reduced to $4.1 \%,(14 / 342,95 \% C I=6.8-2.3 \%)$. Prior to the intervention, cattle in 15 of the 20 study villages had T. $b$. rhodesiense prevalences ranging from 1 to $5 \%$. $T$. $b$. rhodesiense was not detected in any cattle in three $\mathrm{HAT}^{+\mathrm{ve}}$ villages and two $\mathrm{HAT}^{-\mathrm{ve}}$ villages. Six months post-intervention, only eight of the 20 study villages contained T. $b$. rhodesiense positive cattle; $75 \%(6 / 8)$ of these were from $\mathrm{HAT}^{+\mathrm{ve}}$ villages. The locations of villages harbouring cattle infected with $T . b$. rhodesiense before and after intervention are shown in Fig. 6.

\section{AAT}

Prior to the intervention, the prevalence of $T$. vivax in HAT $^{+ \text {ve }}$ village cattle was $5.7 \%(49 / 854,95 \% C I=7.5-$ $4.3 \%)$ and $6.1 \%(49 / 804,95 \% C I=8.0-4.5 \%)$ in HAT $^{-v e}$ villages. At 6 months post-intervention, no T. vivax infected cattle were found in the $\mathrm{HAT}^{+\mathrm{ve}}$ villages $(0 / 956$, 95\% $C I=0.4-0 \%, P<0.0001)$ and only a single case of $T$. vivax in HAT $^{-v e}$ villages was observed $(0.1 \% ; 1 / 935,95 \%$ $C I=0.6-0.0 \%, P<0.0001)$. This is a significant reduction in prevalence, from $6 \%(98 / 1658)$ pre-intervention to $0.05 \%(1 / 1891) 6$ months after intervention. There was

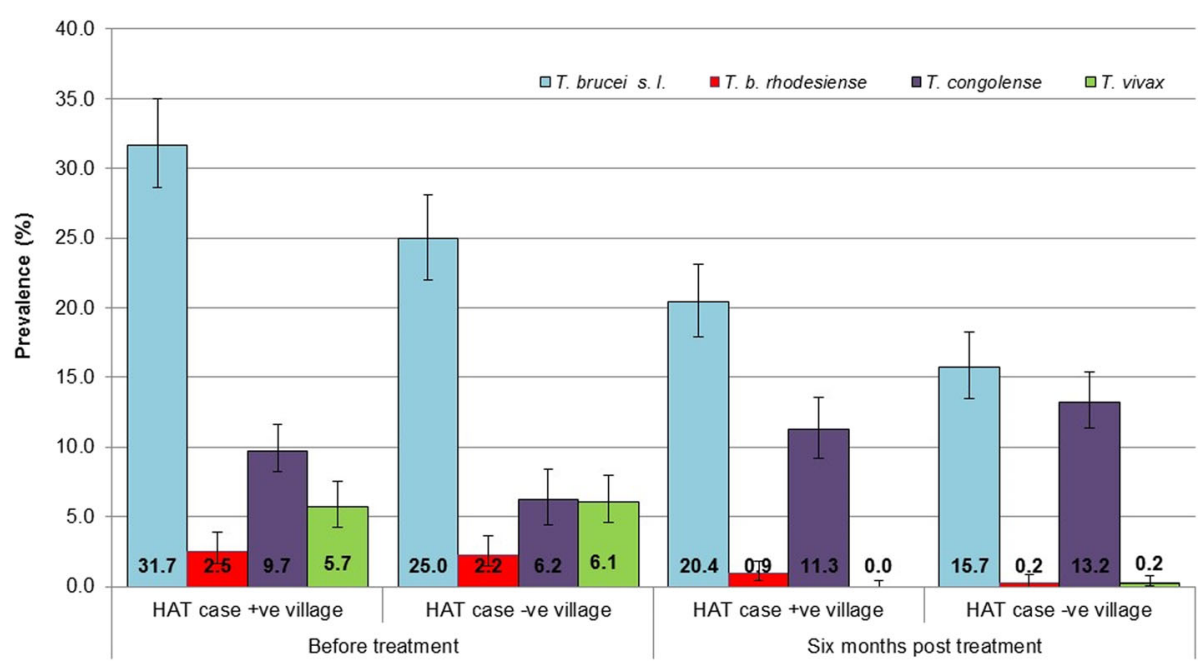

Fig. 4 Prevalence of trypanosome species and sub-species (T. brucei s.l., T. b. rhodesiense, T. congolense and T. vivax) pre- and 6-months post-intervention 


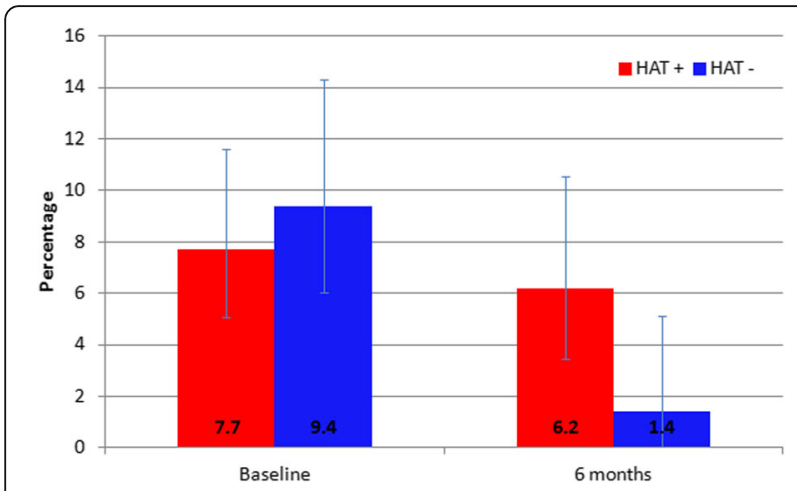

Fig. 5 Proportion of T. brucei s.l. that are T. b. rhodesiense (infective for humans) pre- and post-intervention in $\mathrm{HAT}^{\mathrm{vv}}$ and $\mathrm{HAT}^{\mathrm{ve}}$ study villages ( $95 \%$ confidence intervals indicated)

no significant difference in the prevalence of $T$. vivax in cattle from villages defined as $\mathrm{HAT}^{+\mathrm{ve}}$ or $\mathrm{HAT}^{-\mathrm{ve}}$ either before or after intervention.

Infection in cattle with $T$. congolense savannah was significantly greater than $T$. vivax, both before and after intervention $(P=0.0043)$ (Table 3$)$. In total, the prevalence of $T$. congolense savannah increased from $8 \%(133 / 1$ 658) to
Table 3 Prevalence of Trypansoma vivax and Trypanosoma congolense savannah species pathogenic for cattle, in $\mathrm{HAT}^{+\mathrm{ve}}$ and $\mathrm{HAT}^{-\mathrm{ve}}$ villages before and after intervention

\begin{tabular}{llll}
\hline & $\begin{array}{l}\text { Village HAT } \\
\text { status }\end{array}$ & $\begin{array}{l}\text { Prevalence } T . \\
\text { vivax }\end{array}$ & $\begin{array}{l}\text { Prevalence T. congolense } \\
\text { savannah }\end{array}$ \\
\hline Pre-intervention & HAT $^{+v e}$ & $5.7 \%(7.51-4.27 \%)$ & $9.7 \%(11.91-7.82 \%)$ \\
& HAT $^{+v e}$ & $6.1 \%(7.98-4.54 \%)$ & $6.7 \%(8.67-5.09 \%)$ \\
& Total & $5.9 \%(7.16-4.87 \%)$ & $8.0 \%(9.43-6.81 \%)$ \\
Six months post- & HAT $^{+v e}$ & $0 \%(0.39-0 \%)$ & $11.3 \%(13.48-9.36 \%)$ \\
intervention & HAT $^{\text {-ve }}$ & $0.1 \%(0.41-0.01 \%)$ & $13.2 \%(15.48-11.13)$ \\
& Total & $0.05 \%(0.30-0 \%)$ & $12.2 \%(13.77-10.81 \%)$ \\
\hline
\end{tabular}

Brackets indicate $95 \%$ confidence intervals

$12.2 \%(231 / 1891)$. In cattle from $\mathrm{HAT}^{\text {+ve }}$ villages there was no significant difference in the prevalence of $T$. congolense savannah before $(9.7 \%$; 83/854, 95\% CI $=11.9$ $7.8 \%)$ or after intervention $(11.3 \%$; $108 / 956,95 \% C I=$ $13.5-9.4 \%)(P=0.2842)$. In cattle from HAT $^{-v e}$ villages the prevalence of $T$. congolense savannah before intervention was $6.7 \%(54 / 804,95 \% C I=8.7-5.1 \%)$, significantly lower than in $\mathrm{HAT}^{+\mathrm{ve}}$ villages $(P=0.0319)$. Six months post-intervention, the prevalence of $T$. congolense

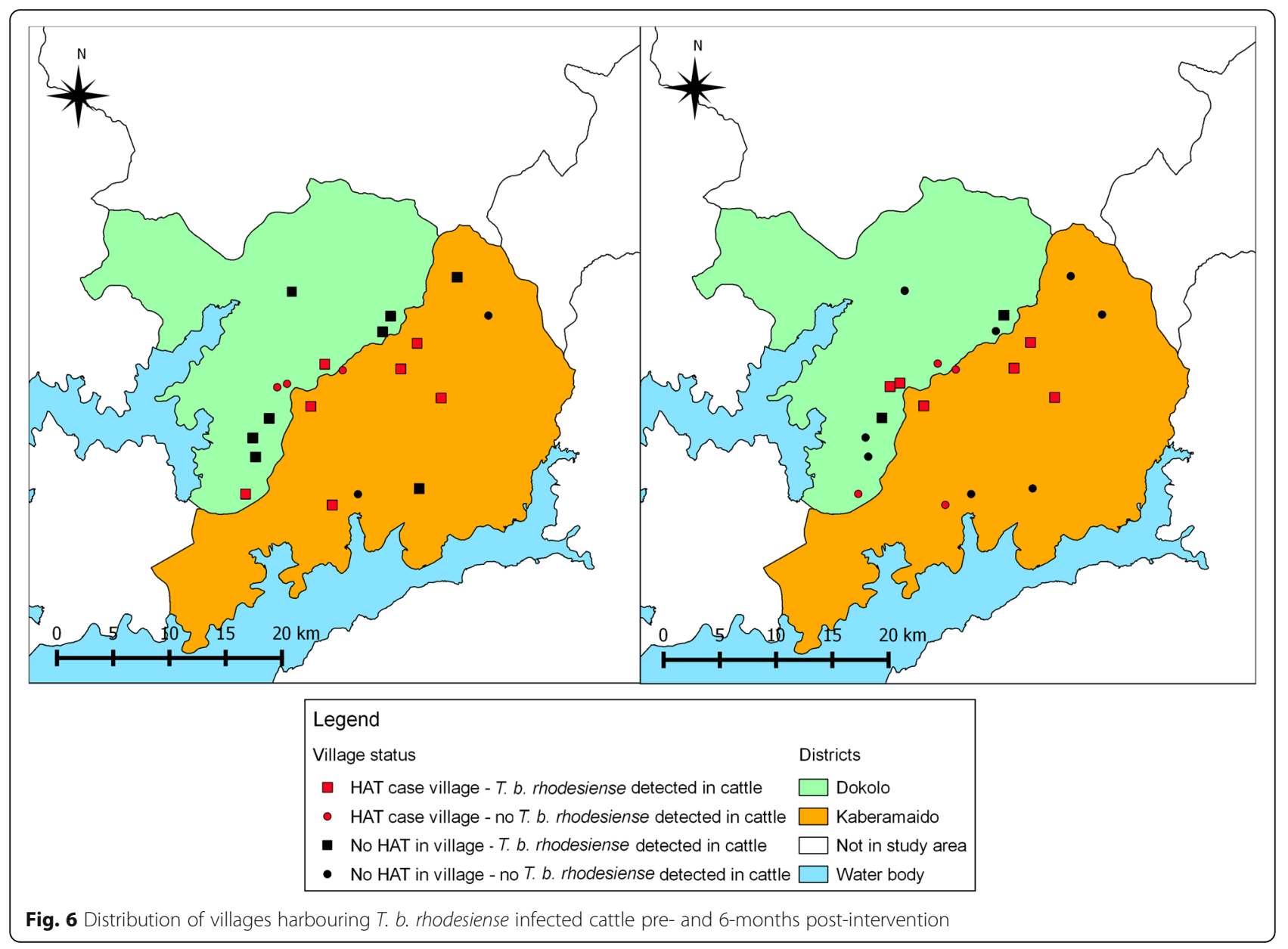


savannah of $13.2 \%$ significantly increased (123/935, 95\% $C I=15.5-11.1 \%, P<0.0001)$.

\section{Intervention coverage}

Mathematical modelling estimated that to interrupt T. $b$. rhodesiense transmission, where cattle were the principal reservoir of $T . b$. rhodesiense, required treatment of $86 \%$ of the cattle population [22]. Between April and May 2008, SOS reported administering a trypanocide to 31 , 486 head of cattle across 29 parishes in Dokolo and Kaberamaido. Estimations of intervention coverage were based on the total number of cattle treated, the 2008 livestock census data and farmer based reporting 6 months post-intervention. The livestock census was based on household survey data collected at a fixed number of points within each district throughout Uganda; this was modelled to parish level, based on demographic trends and other data, by district-level staff. The exact methodology employed is uncertain, and the parish level data are of variable quality. The 2008 census data were conservatively inflated by $20 \%$ on the advice of the District Veterinary Officers in Dokolo and Kaberamaido to allow for population growth and importation from other districts as part of national restocking programs as well as trade (Table 2).

In Dokolo district, 10820 out of an estimated 11, 809 head of cattle from 13 parishes were treated (91.6\%) - 20\% of the total estimated cattle population of Dokolo district (58 902). In Kaberamaido, 20666 cattle were treated from 16 parishes with an estimated cattle population of 16919 head, giving estimated coverage of $122 \%$ or $27 \%$ of the total cattle population in the district (76 109 head). Of the 29 parishes, eight showed coverage below $60 \%$ while 11 parishes showed coverage $>100 \%$; six parishes had more than $200 \%$ estimated coverage.

Six months after the intervention, livestock-keepers in the 20 study villages were asked to report whether their animals had participated in the intervention. According to the livestock-keepers, $55.2 \%$ (1 044/1891) of the cattle sampled 6 months after the intervention had participated in the intervention (Table 4). Fewer animals, 51\% (486/ 956), were reported to have participated in the $\mathrm{HAT}^{+\mathrm{ve}}$ villages than in the $\mathrm{HAT}^{-\mathrm{ve}}$ villages, 59.7\% (558/935).

Intervention coverage impacted on identification of Trypanosoma infection by PCR (Table 4). Of the 342 animals found positive for T. brucei s.l., $47 \%$ at the 6 month post-intervention sampling were from cattle that had not participated in the intervention (162/342). Within the $\mathrm{HAT}^{+\mathrm{ve}}$ villages $52 \%(101 / 195)$ of the animals found positive for $T$. brucei, had not participated in the intervention. Of the $12 T . b$. rhodesiense infections identified in $\mathrm{HAT}^{+\mathrm{ve}}$ villages, 66\% (8/12) were observed in cattle reported not to have particpated in the intervention. Of the $231 T$. congolense infections identified 37\% were from animals reported not to have participated in the intervention and $63 \%$ from those reported to have particpated.

\section{Discussion}

Microscopy consistently underestimates the prevalence trypanosomes in livestock $[38,39]$, so the use of sensitive and specific 'field friendly' diagnostic tools are key to our understanding of the epidemiology of bovine and zoonotic trypanosomiasis [39]. Cattle have been shown to play a major role in the epidemiology of rHAT in Uganda [6-9, 21, 33]. This is one of the first studies to use molecular tools to evaluate large-scale field interventions targeted at $T$. $b$. rhodesiense, the causal agent of rHAT, in cattle - the principal animal reservoir. Previous studies have shown the importance of eliminating the reservoir of human infective $T . b$. rhodesiense parasites from domestic cattle to prevent human infection [21,32].

Across the 20 randomly selected villages within the intervention zone we observed a significant reduction of T. b. rhodesiense in cattle 6 months after the intervention (from 2.40 to $0.74 \%$ ), a 10 -fold decrease in prevalence of $T . b$. rhodesiense in $\mathrm{HAT}^{-\mathrm{ve}}$ villages compared to a $50 \%$ reduction of $T$. b. rhodesiense in $\mathrm{HAT}^{+\mathrm{ve}}$ villages. The number of villages with $T . b$. rhodesiense

Table 4 Trypanosoma infection and intervention participation status of cattle sampled at 6 months post-intervention as reported by livestock-keepers

\begin{tabular}{|c|c|c|c|c|c|c|c|c|c|c|}
\hline Village HAT status & Intervention participation & Cattle sampled (n) & $\mathrm{TBSL}+(n)$ & $\%$ TBSL + & $\mathrm{SRA}+(n)$ & $\%$ SRA + & $\mathrm{TV}+(n)$ & $\%$ TV + & $\mathrm{TC}+(n)$ & $\% \mathrm{TC}+$ \\
\hline \multirow[t]{4}{*}{ HAT + villages } & & 956 & 195 & 20.4 & 12 & 1.3 & 0 & 0 & 108 & 11.3 \\
\hline & Unknown & 32 & 5 & 15.6 & 0 & 0 & 0 & 0 & 3 & 9.4 \\
\hline & Intervention & 486 & 89 & 18.3 & 4 & 0.8 & 0 & 0 & 56 & 11.5 \\
\hline & No intervention & 438 & 101 & 23.1 & 8 & 1.8 & 0 & 0 & 49 & 11.2 \\
\hline \multirow[t]{4}{*}{ HAT - villages } & & 935 & 147 & 15.7 & 2 & 0.2 & 1 & 0.1 & 123 & 13.2 \\
\hline & Unknown & 27 & 0 & 0 & 0 & 0 & 0 & 0 & 4 & 14.8 \\
\hline & Intervention & 558 & 86 & 15.4 & 1 & 0.2 & 1 & 0.2 & 83 & 14.9 \\
\hline & No intervention & 350 & 61 & 17.4 & 1 & 0.3 & 0 & 0 & 36 & 10.3 \\
\hline
\end{tabular}

NB: TBSL + - sample positive for T. brucei s.l; SRA + sample positive for human infective $T$. $b$. rhodesiense; TV + sample positive for $T$. vivax; TC + sample positive for T. congolense savannah 
infected cattle fell from 15 to eight villages posttreatment; most T. b. rhodesiense infected cattle postintervention were from villages that had a case of human rHAT (six of the eight infected villages). This emphasises the focal nature of rHAT [33, 40] suggesting that once T. $b$. rhodesiense is established in a village, spilling over from cattle into humans, eliminating the cattle reservoir of T. b. rhodesiense in the village becomes more difficult.

HAT transmission is influenced by many factors, including tsetse population density, tsetse susceptibility [41] and proximity to around a central point such as a market, watering point or swampland $[8,10,40]$. In this study villages that had experienced a case of rHAT also showed a significantly higher prevalence of $T$. brucei s.l. and $T$. congolense in the village cattle than those that had not had a case of rHAT, further evidence of a link between AAT and T. $b$. rhodesiense HAT. Conditions for transmission of all species of trypanosome appeared more favourable in $\mathrm{HAT}^{+\mathrm{ve}}$ villages.

T. vivax all but disappeared across the study villages post-intervention, but the prevalence of $T$. congolense increased (although a large proportion of infected animals had not participated in the intervention). Drug resistance in cattle has been reported for $T$. congolense in parts of Ethiopia [42] and Burkina Faso [43] but this has not been reported in Uganda where T. congolense infection is rarely reported or treated. Eliminating T. vivax and reducing $T$. brucei s.l. in cattle may simply offer opportunities for $T$. congolense to establish in these animals [44].

To interrupt $T . b$. rhodesiense transmission, where cattle are the principal reservoir of T. $b$. rhodesiense, it is calculated that $86 \%$ of the cattle population must be treated [22]. The discrepancy between the coverage estimates calculated from the livestock census data (91.3\%) and the lower estimates obtained provided from the livestock-keepers (55.2\%) show the difficulties of calculating coverage in the absence of robust and verifiable village and parish cattle numbers; true coverage probably lay somewhere between the two.

In Dokolo, cattle were treated in 13 of 33 parishes in the district, or $39 \%$ of the district; coverage was estimated at $20 \%$ of the district cattle. Likewise, for Kaberamaido, the mass intervention covered $50 \%$ of the district (16 of 32 parishes) but using, 2008 livestock census data, only 27\% of the district cattle population are estimated to have been treated. The parishes treated during the mass intervention had relatively low cattle populations compared to other areas of the district.

Accurate information about the number of cattle owned by individuals and households in this region is difficult to obtain. Extensive cattle rustling in the late 1980s decimated livestock in the region and the Lango and Teso economy [45] and cattle restocking projects [46] were ongoing during 2008 when this intervention took place [13]. Villagers may answer questions about donor-led interventions in ways that take into account how their answers will influence future benefits [47] and it is likely that a proportion of livestock-keepers misrepresented the treatment status of their cattle in the hope that their herd would be re-treated.

\section{Conclusions}

Treatment of cattle produced a significant decrease in the prevalence of $T$. brucei s.l, human infective $T$. $b$. rhodesiense and T. vivax infection in village cattle herds and impacted on the proportion of T. brucei s.l. that were human infective: from 1:12 human infective T. brucei s.l. before the intervention to $1: 33$ post-intervention.

The observation that is more difficult to remove $T . b$. rhodesiense from villages that have experienced a rHAT case, makes a strong case for improved information sharing between human health providers, animal health providers and the community. The prevalence of AAT in villages can serve as an additional indicator of human health risk in these communities, alerting medical services to survey human populations. Incorporating participatory research in conjunction with traditional disease modelling approaches could lead to improved disease control [48].

To prevent the continued migration of rHAT, point of sale trypanocide treatments should be applied for all inter-district cattle movements and interventions that target rHAT and AAT should be scaled up in all rHAT affected districts. Interventions that additionally target tick-borne diseases are welcomed by local communities [45], where trypanosomiasis and tick-borne diseases reduce draft cattle output by $21 \%$ and household income from the use of oxen (estimated at \$245 USD annually) by $32 \%$ [49]. Appropriate scaled application of trypanocidal drugs, followed by routine application of veterinary pyrethroids to prevent re-infection and manage tick infestation, offer a sustainable solution for zoonotic HAT, AAT and tick-borne disease control [29, 31, 49, 50] offering a win-win for human and animal health.

\section{Additional file}

Additional file 1: Multilingual abstracts in the six official working languages of the United Nations. (PDF 862 kb)

\section{Abbreviations}

AAT: Animal African Trypanosomiasis; COCTU: The Coordinating Office for Control of Trypanosomiasis in Uganda; DVO: District Veterinary Officer; gHAT: T.b. gambiense HAT; HAT: Human Animal Trypanosomaisis; ICONZ: Integrated Control of Neglected Zoonoses; LRA: Lord's resistance army; PCR: Polymerase chain reaction; PPP: Public Private Partnership; rHAT: T.b. rhodesiense HAT; SOS: Stamp out Sleeping Sickness

\section{Acknowledgements}

The authors would like to thank all those involved in this study, particularly those who participated in sample collection in the field; Bernard Agwai and Joseph Ssempijja, the District Veterinary Officers and their staff and all the 
cattle owners who made their animals available. The authors would like to thank the Stamp Out Sleeping Sickness teams and staff of Makerere University who delivered the intervention.

\section{Funding}

This study was funded with UK aid from the UK government' under the DfID Research into Use Programme (SCW, LH, KP, KP, KLB, CW, JDK) and from the European Union's Seventh Framework Program (FP7/2007-2014) under grant agreement $n^{\circ} 221948$ Integrated Control of Neglected Zoonoses (ICONZ) (SCW, KP, KLB, CW, JDK). Treatment of village cattle was undertaken under the Stamp Out Sleeping Sickness Programme supported by IKARE and Ceva Santé Animale. The funders had no role in study design, data collection and analysis, decision to publish, or preparation of the manuscript.

\section{Availability of data and materials}

All data and materials are available on request from the corresponding author

\section{Authors' contributions}

Conceived and designed the study: SCW, KP, CW, JDK. Undertook PCR analysis: $\mathrm{LH}, \mathrm{KP}$, JF. Analysed the data: $L H, K P, K L B, S C W$. Participated in sample collection and processing: SW, BVW, JF, RS, CAA. Contributed reagents/materials/analysis tools: KP, CW, NW. Prepared the manuscript: SCW, LH, KP, KLB, CW, JDK. Al authors read and approved the final manuscript.

\section{Competing interests}

The authors declare that they have no competing interests.

\section{Consent for publication}

All authors have consented to publication.

\section{Ethics approval and consent to participate}

Informed consent was obtained from the client or owner of the animal and protocols employed adhered to the highest standard (best practice) of veterinary care. Blood was taken from cattle by qualified and experienced Ugandan Veterinary personnel. At the national and district levels, the study was conducted with the approval of the Coordinating Office for Contro of Trypanosomiasis in Uganda (COCTU) as well as the District Veterinary Officers (DVOs) in each of the study districts.

\section{Author details}

'Edinburgh Infectious Diseases, Division of Infection and Pathway Medicine, Edinburgh Medical School: Biomedical Sciences, The University of Edinburgh, Chancellor's Building, 49 Little France Crescent, Edinburgh EH16 4SB, UK. ${ }^{2}$ Department of Pharmacy, Clinical and Comparative Medicine, School of Veterinary Medicine and Animal Resources, Makerere University, P.O. Box 7062, Kampala, Uganda. ${ }^{3}$ The Coordinating Office for Control of Trypanosomiasis in Uganda (COCTU), Wandegeya, Plot 76/78 Buganda Road, P.O. Box 16345, Kampala, Uganda.

Received: 3 March 2016 Accepted: 15 December 2016

\section{Published online: 06 February 2017}

\section{References}

1. Welburn SC, Fèvre EM, Coleman PG, Odiit M, Maudlin I. Sleeping sickness: a tale of two diseases. Trends Parasitol. 2001;17:19-24.

2. Fèvre EM, Coleman PG, Welburn SC. Maudlin I Reanalyzing the 1900-1920 sleeping sickness epidemic in Uganda. Emerg Infect Dis. 2004;10(4):567-73.

3. Welburn SC, Molyneux DH. Maudlin I Beyond tsetse - implications for research and control of human African trypanosomiasis epidemics. Trends Parasitol. 2016;32(3):230-41.

4. Mugenyi A, Wardrop NA, Atkinson PM, Torr SJ, Welburn SC. Tsetse fly (G. f. fuscipes) distribution in the Lake Victoria Basin of Uganda. PLoS Negl Trop Dis. 2015;9(4), e0003705

5. Odiit M, Coleman PG, McDermott JJ, Fevre EM, Welburn SC, Woolhouse MEJ. Spatial and temporal risk factors for the early detection of Trypanosoma brucei rhodesiense sleeping sickness patients in Tororo and Busia districts, Uganda. Trans Roy Soc Trop Med Hyg. 2004;98:569-76.

6. Hide G, Welburn SC, Tait A, Maudlin I. Epidemiological relationships of Trypanosoma brucei stocks from South East Uganda: evidence for different population structures in human infective and non-human infective isolates. Parasitol. 1994;109:95-111.
7. Welburn SC, Picozzi K, Fèvre E, Coleman P, Odiit M, et al. Identification of human-infective trypanosomes in animal reservoir of sleeping sickness in Uganda by means of serum-resistance-associated (SRA) gene. Lancet. 2001; 358:2017-9.

8. Fèvre EM, Coleman P, Odiit M, Magona JW, Welburn SC, et al. The origins of a new Trypanosoma brucei rhodesiense sleeping sickness outbreak in eastern Uganda. Lancet. 2001;358:625-8.

9. Fèvre EM, Picozzi K, Fyfe J, Waiswa $C$, Odiit $M$, et al. A burgeoning epidemic of sleeping sickness in Uganda. Lancet. 2005;366:745-7.

10. Batchelor NA, Atkinson PM, Gething PW, Picozzi K, Fèvre EM, et al. Spatial predictions of Rhodesian human African trypanosomiasis (sleeping sickness) prevalence in Kaberamaido and Dokolo, two newly affected districts of Uganda. PLoS Negl Trop Dis. 2009;3, e563.

11. Picozzi K, Févre E, Odiit M, Carrington M, Eisler MC, et al. Sleeping sickness in Uganda: a thin line between two fatal diseases. BMJ. 2005:331:1238-41.

12. Anderson NE, Mubanga J, Fevre EM, Picozzi K, Eisler M, Thomas R, Welburn SC. Characterisation of the wildlife reservoir community for human and animal trypanosomiasis in the Luangwa Valley, Zambia. PLoS Negl Trop Dis. 2011:5(6), e1211.

13. Selby R, Bardosh K, Picozzi K, Waiswa C, Welburn SC. Cattle movements and trypanosomes: Restocking efforts and the spread of Rhodesian sleeping sickness in post-conflict Uganda. Parasit Vectors. 2013;6:281.

14. Berrang-Ford L, Garton K. Expert knowledge sourcing for public health surveillance: National tsetse mapping in Uganda. Soc Sci Med. 2013;91:246-55.

15. Ministry of Agriculture: Animal Industry and Fisheries, Uganda; Uganda Bureau of Statistics; Food and Agriculture; Organization of the United Nations; International Livestock Research Institute; and World Resources Institute. Mapping a better future: Spatial analysis and pro-poor livestock strategies in Uganda. Washington, DC and Kampala: World Resources Institute; 2010.

16. Kristjanson PM, Swallow BM, Rowlands GJ, Kruska RL, de Leeuw PN. Measuring the costs of African animal trypanosomosis, the potential benefits of control and returns to research. Agric Sys. 1999;59:79-98.

17. Welburn SC, Maudlin I, Simarro PP. Controlling sleeping sickness: a review. Parasitol. 2009:136:1943-9.

18. Odiit M, Coleman PG, Liu W-C, McDermott JJ, Fevre EM, Welburn SC, Woolhouse MEJ. Quantifying the level of under-detection of Trypanosoma brucei rhodesiense sleeping sickness cases. Trop Med Int Health. 2005;10:840-9.

19. Acup C, Picozzi K, Waiswa C, Welburn SC. Factors influencing passive surveillance for zoonotic T. b. rhodesiense human African trypanosomiasis in Uganda. Acta Trop. 2016. doi:10.1016/j.actatropica.2016.05.009.

20. Wendo C. Uganda revises cattle treatment to protect humans from sleeping sickness. Lancet. 2002;359(9302):239.

21. Fyfe J, Picozzi K, Bardosh K, Waiswa C, Welburn SC. Impact of masschemotherapy in domestic livestock for control zoonotic T. b. rhodesiense human African trypanosomiasis in Eastern Uganda. Acta Trop. 2016; doi:10. 1016/j.actatropica.2016.08.022

22. Welburn SC, Coleman PG, Fèvre EM, Odiit M, Maudlin I, Eisler MC. Crisis, what crisis? Control of Rhodesian sleeping sickness. Trends Parasitol. 2006;22:123-8.

23. Kabasa JD. Public-private partnership works to stamp out sleeping sickness in Uganda. Trends Parasitol. 2007;23(5):191-2.

24. Welburn SC, Coleman P. Human and animal African trypanosomiasis. In One Health, The theory and practice of integrated health approaches. Editors: Zinsstag J, Schelling E, Waltner-Toews D, Whittaker M, Tanner M. Oxford, UK and Boston: CABI International; 2015. p. 201-21. ISBN: 9781780643410

25. Uganda National Census, 2002. Uganda Bureau of Statistics; 2008.

26. Uganda districts information handbook. Kampala: Fountain Publishers; 2007.

27. Wardrop NA, Atkinson PM, Gething PW, Picozzi K, Fèvre EM, Kakembo A, Welburn SC. Bayesian geostatistical analysis and prediction of Rhodesian human African trypanosomiasis. PLoS Negl Trop Dis. 2010;4(12):e914.

28. Bardosh K, Waiswa C, Welburn S. Conflict of interest: use of pyrethroids and amidines against tsetse and ticks in zoonotic sleeping sickness endemic areas of Uganda. Parasit Vectors. 2013;6:204.

29. Torr SJ, Maudlin I, Vale G. Less is more: restricted application of insecticide to cattle to improve the cost and efficacy of tsetse control. Med Vet Entomol. 2007;21:53-64.

30. Muhanguzi D, Picozzi K, Hatendorf J, Thrusfield M, Welburn SC, et al. Improvements on restricted insecticide application protocol for control of human and animal African Trypanosomiasis in Eastern Uganda. PLoS Negl Trop Dis. 2014;8:e3284.

31. Kajunguri D, Hargrove JW, Ouifki R, Mugisha JYT, Coleman PG, Welburn SC. Modelling the control of tsetse and Trypanosoma brucei rhodesiense in a 
multi-host population through insecticide-treated cattle. Bull Math Biol. 2014. doi:10.1007/s11538-014-9938-6.

32. Dohoo I, Martin W, Stryhn H. Veterinary epidemiologic research. Charlottetown: VER Inc; 2003.

33. Thrusfield M. Veterinary epidemiology. Oxford: Blackwell Science; 2005.

34. von Wissmann B, Fyfe J, Picozzi K, Hamill L, Waiswa C, et al. Quantifying the association between bovine and human Trypanosomiasis in newly affected sleeping sickness areas of Uganda. PLoS Negl Trop Dis. 2014;8, e2931.

35. Ahmed H, MacLeod E, Hide G, Welburn S, Picozzi K. The best practice for preparation of samples from FTA' cards for diagnosis of blood borne infections using African trypanosomes as a model system. Parasit Vectors. 2011;4:68.

36. Masake RA, Majiwa PAO, Moloo SK, Makau JM, Njuguna JT, et al. Sensitive and specific detection of Trypanosoma vivax using the polymerase chain reaction. Exp Parasitol. 1997;85:193-205.

37. Moser DR, Cook GA, Ochs DE, Bailey CP, McKane MR, et al. Detection of Trypanosoma congolense and Trypanosoma brucei subspecies by DNA amplification using the polymerase chain reaction. Parasitol. 1989;99:57-66.

38. Picozzi K, Carrington M, Welburn SC. A multiplex PCR that discriminates between Trypanosoma brucei brucei and zoonotic T. b. rhodesiense. Exp Parasitol. 2008;118:41-6.

39. Mugittu KN, Silayo RS, Majiwa PAO, Kimbita EK, Mutayoba BM, et al. Application of PCR and DNA probes in the characterisation of trypanosomes in the blood of cattle in farms in Morogoro, Tanzania. Vet Parasitol. 2001;94:177-89.

40. Okello AL, Welburn SC. The importance of veterinary policy in preventing the emergence and re-emergence of zoonotic disease: examining the case of human African trypanosomiasis in Uganda. Front Public Health. 2014;2:218.

41. Zoller T, Fèvre EM, Welburn SC, Odiit M, Coleman PG. Analysis of risk factors for $T$. brucei rhodesiense sleeping sickness within villages in south-east Uganda. BMC Infect Dis. 2008;30(8):88.

42. Mulugeta W, Wilkes J, Mulatu W, Majiwa PAO, Masake R, et al. Long-term occurrence of Trypanosoma congolense resistant to diminazene, isometamidium and homidium in cattle at Ghibe. Ethiopia Acta Tropic. 1997;64:205-17.

43. Clausen PH, Sidibe I, Kaborè I, Bauer B. Development of multiple drug resistance of Trypanosoma congolense in Zebu cattle under high natural tsetse fly challenge in the pastoral zone of Samorogouan, Burkina Faso. Acta Tropic. 1992;51:229-36.

44. Welburn SC, Picozzi K, Coleman PG, Packer C. Patterns in age-seroprevalence consistent with acquired immunity against Trypanosoma brucei in Serengeti lions. PLoS Negl Trop Dis. 2008:2(12):e347.

45. Bardosh KL. Deadly flies, poor profits and veterinary pharmaceuticals: sustaining the control of sleeping sickness in Uganda. Med Anthropol. 2016;35(4):338-52. doi:10.1080/01459740.2015.1101461.

46. Jones B. Beyond the state in rural Uganda. Edinburgh: Edinburgh University Press for the International African Institute; 2009. p. 199.

47. Fairhead J, Leach M, Small M. Where techno-science meets poverty: medical research and the economy of blood in The Gambia, West Africa. Soc Sci Med. 2006;63(4):1109-20.

48. Grant C, Lo lacono G, Dzingirai V, Bett B, Winnebah T, Atkinson PM. Moving interdisciplinary science forward: integrating participatory modelling with mathematical modelling of zoonotic disease in Africa. Infect Dis Poverty. 2016;5:17. doi:10.1186/s40249-016-0110-4.

49. Okello WO, Muhanguzi D, MacLeod ET, Welburn SC, Waiswa C, Shaw AP. Contribution of draft cattle to rural livelihoods in a district of southeastern Uganda endemic for bovine parasitic diseases: an economic evaluation. Parasit Vectors. 2015;8(1):1-9.

50. Muhanguzi D, Okello WO, Kabasa JD, Waiswa C, Welburn SC, Shaw APM. Cost analysis of options for management of African animal trypanosomiasis using interventions targeted at cattle in Tororo District; south-eastern Uganda. Parasit Vectors. 2015;8:387. doi:10.1186/s13071-015-0998-8. 